\title{
Efeito do extrato aquoso de alecrim (Rosmarinus officinalis L.) sobre o estresse oxidativo em ratos diabéticos ${ }^{1}$
}

\author{
Effect of aqueous rosemary extract \\ (Rosmarinus officinalis L.) on the \\ oxidative stress of diabetic rats
}

Ana Mara de Oliveira e SILVA

Elma Regina Silva de ANDRADE-WARTHA ${ }^{3}$

Eliane Bonifácio Teixeira de CARVALHO²

Alessandro de $\mathrm{LIMA}^{4}$

Alexis Vidal NOVOA ${ }^{5}$

Jorge MANCINI-FILHO²

RE S U M O

\section{Objetivo}

Avaliar o efeito do extrato aquoso de alecrim sobre o estresse oxidativo em ratos diabéticos.

\section{Métodos}

O extrato aquoso de alecrim foi obtido por método sequencial. Os fenólicos totais foram determinados pelo método de Folin Ciocateau e a atividade antioxidante in vitro foi determinada através de três métodos: $\beta$-caroteno/ácido linoleico, varredura do radical 2,2 Difenil-1-Picril-hidrazil e oxigen radical absorbance capacity. Ratos Wistar machos foram distribuídos em 5 grupos: controle, diabético, e três grupos de animais diabéticos tratados com extrato aquoso de alecrim em concentrações diferentes: 25,50 ou 100 mg/kg por via oral durante 30 dias. O diabetes foi induzido por estreptozotocina e, no final do experimento, foi coletado sangue para avaliar o percentual de hemoglobina glicada e os tecidos hepático e cerebral para determinação das enzimas antioxidantes: superóxido dismutase, catalase, glutationa peroxidase e glutationa redutase.

1 Artigo elaborado a partir da dissertação de A.M.O. SILVA, intitulada "Efeito dos compostos fenólicos presentes no alecrim (Rosmarinus officinalis L.) sobre as enzimas antioxidantes e os parâmetros bioquímicos do sangue de ratos diabéticos induzidos por estreptozotocina". Universidade de São Paulo; 2008.

2 Universidade de São Paulo, Faculdade de Ciências Farmacêuticas, Departamento de Alimentos e Nutrição Experimental. Av. Professor Lineu Prestes, 580, Bloco 14, Cidade Universitária, 05508-900, São Paulo, SP, Brasil. Correspondência para/Correspondence to: A.M.O. SILVA. E-mail: <anamara@usp.br>.

3 Universidade Federal de Sergipe, Núcleo de Nutrição. Aracajú, SE, Brasil.

${ }^{4}$ Instituto Federal de Educação, Ciência e Tecnologia. Teresina, PI, Brasil.

5 Universidad de La Habana, Facultad de Biología. La Habana, Cuba. 
122 | A.M.O. SILVA et al.

\section{Resultados}

Constatou-se que o extrato aquoso de alecrim apresentou altos teores de compostos fenólicos totais e expressiva atividade antioxidante in vitro nos três métodos de avaliação. O extrato aquoso de alecrim na concentração de $50 \mathrm{mg} / \mathrm{kg}$ diminuiu o percentual de hemoglobina glicada e aumentou a atividade das enzimas catalase e glutationa peroxidase no fígado, e da superóxido dismutase no cérebro de ratos diabéticos. No entanto, não foi observado efeito dose-resposta nas demais concentrações analisadas.

\section{Conclusão}

O extrato aquoso de alecrim apresenta significativa capacidade antioxidante in vitro, atribuída à presença de compostos fenólicos em sua composição. E, quando administrado em ratos na concentração de $50 \mathrm{mg} / \mathrm{kg}$, demonstrou-se eficiente na atenuação do estresse oxidativo presente no diabetes experimental.

Termos de indexação: Antioxidantes. Compostos fenólicos. Diabetes mellitus. Enzimas. Rosmarinus.

\section{A B S T R A C T}

\section{Objective}

This study assessed the effect of aqueous rosemary extract on the oxidative stress of diabetic rats.

\section{Methods}

Aqueous rosemary extract was obtained by the sequential method. Total phenolic content was determined by the Folin Ciocateau method and antioxidant activity in vitro was determined by the following methods: $\beta$-carotene/linoleic acid, 2,2 Difenil-1-Picril-hidrazil and oxygen radical absorbance capacity. Male Wistar rats were distributed into 5 groups: control, diabetic, and three groups of diabetic animals treated with aqueous rosemary extract in different concentrations: 25,50 or $100 \mathrm{mg} / \mathrm{kg}$ orally for 30 days. Diabetes was induced by streptozotocin and, at the end of the experiment, blood was collected to assess the percentage of glycated hemoglobin; liver and brain tissues were collected for the determination of the antioxidant enzymes: superoxide dismutase, catalase, glutatione peroxidase and glutatione reductase.

\section{Results}

Aqueous rosemary extract contains high levels of phenolic compounds and significant total antioxidant activity in vitro according to the three methods. Aqueous rosemary extract at a concentration of $50 \mathrm{mg} / \mathrm{kg}$ decreased the percentage of glycated hemoglobin and increased the activity of glutatiose peroxidase and catalase enzymes in the liver and superoxide dismutase in the brain of diabetic rats. However, no dose-response effect was observed in the other concentrations.

\section{Conclusion}

Aqueous rosemary extract presented significant antioxidant capacity in vitro attributed to its high phenolic compound content. When administered to rats at a concentration of $50 \mathrm{mg} / \mathrm{kg}$, it proved to be efficient against the oxidative stress secondary to experimental diabetes.

Indexing terms: Antioxidants. Phenolic compounds. Mellitus diabetes. Enzymes. Rosemarinus.

\section{N T R O D U ÇÃ O}

O diabetes Mellitus é considerado um problema mundial de saúde pública; cuja incidência e prevalência aumentam cada vez mais, alcançando proporções epidêmicas. Estima-se que cerca de 143 milhões de pessoas em todo o mundo sofram de diabetes e acredita-se que esse número possa dobrar até 2030, quando o Brasil ocupará a sexta posição, com 11,3 milhões de $\operatorname{casos}^{1,2}$.

O diabetes está associado a complicações que comprometem a qualidade de vida e a sobre- vida dos indivíduos. Além disso, acarreta elevados custos para o controle metabólico e o tratamento de suas complicações ${ }^{3}$.

O estresse oxidativo no diabetes, com aumento das espécies reativas na mitocôndria, está associado a vários mecanismos envolvendo a hiperglicemia como fator principal, que resulta na estimulação de quatro vias principais: via do poliol, produção intracelular dos precursores dos produtos de Glicação Avançada (AGE), ativação da Proteína Quinase C (PKC) e ativação da via da hexosamina ${ }^{4-7}$. 
As espécies reativas formadas nos processos fisiológicos estão envolvidas com diferentes alterações metabólicas como: peroxidação lipídica, glicação de proteínas, inativação de enzimas e alteração nas estruturas celulares e, consequentemente, com danos ao organismo ${ }^{4,7}$.

A glicação da hemoglobina já é bem definida ${ }^{8,9} \mathrm{e}$, por se tratar de uma reação oxidativa, os antioxidantes seriam capazes de prevenir a glicação das proteínas ${ }^{10}$.

Já o comportamento das enzimas antioxidantes frente ao estresse oxidativo no diabetes ainda é bem controverso. Estudos mais recentes $^{11,12}$ demonstraram que há depleção no mecanismo de defesa antioxidante no diabetes, com alterações na atividade das enzimas antioxidantes. Com isso, crescem as investigações sobre o efeito de substâncias com propriedades antioxidantes, uma vez que as defesas antioxidantes endógenas não são suficientes para manter os níveis normais de espécies reativas no diabetes. Nesse contexto, ganham importância os estudos com compostos fenólicos ${ }^{13-15}$.

$\mathrm{O}$ alecrim (Rosmarinus officinalis L.) tem sido bastante utilizado na indústria de alimentos e apreciado por suas propriedades: aromática, antioxidante, antimicrobiana e antitumoral. Nos extratos de alecrim podem ser encontrados três grupos de compostos fenólicos: diterpenos fenólicos, flavonoides e ácidos fenólicos. O ácido carnósico, o carnosol, os diterpenos e o ácido rosmarínico são os principais compostos antioxidantes presentes nessa especiaria ${ }^{16}$.

Sotelo-Félix et al. ${ }^{17}$, estudando o efeito do extrato de alecrim administrado por via oral em ratos na concentração de $200 \mathrm{mg} / \mathrm{kg}$, durante cinco dias, observaram efeito hepatoprotetor contra a injúria aguda provocada por tetracloreto de carbono. O alecrim atuou como antioxidante, eliminando os radicais triclorometilperoxil formados pela metabolização hepática do agente químico agressor, e aumentou a atividade do sistema de desintoxicação dependente da Glutationa S-Transferase (GST).
Considerando ainda seu elevado conteúdo de fenólicos, o extrato aquoso de alecrim apresentou efeito hepatoprotetor também na toxicidade induzida por azatioprina em ratos, reduzindo os níveis de malonaldeído provocado pelo estresse e diminuindo o efeito inibitório do azatioprine sobre a atividade das enzimas Superóxido Dismutase (SOD), Catalase (CAT) e Glutationa Peroxidase $(\mathrm{GPx})^{18}$.

Estudos com extratos de plantas, usados como antioxidantes, testaram doses entre $50 \mathrm{e}$ $100 \mathrm{mg} / \mathrm{kg}^{17}$. Os próprios autores relataram que em doses mais elevadas pode não ser observado o efeito protetor, podendo elas, ao contrário, induzir efeitos tóxicos. Estudos dose-resposta são necessários para se obter a concentração que produza o melhor resultado sem demonstrar reações adversas, demandando uma avaliação toxicológica para atingir tal objetivo.

Considerando o alecrim como uma fonte potencial de compostos fenólicos com propriedades biológicas já bem relatadas na literatura, o objetivo deste trabalho foi avaliar o efeito do extrato aquoso de alecrim sobre o estresse oxidativo em ratos diabéticos.

\section{MÉ TODOS}

O Extrato Aquoso (EA) de alecrim foi obtido pelo método de extração seqüencial, com solventes de diferentes polaridades a partir da amostra triturada ${ }^{19}$.

Os fenólicos totais foram determinados utilizando o reagente Folin Ciocateau ${ }^{20}$. Foi feita uma curva padrão com ácido gálico, sendo os resultados expressos em equivalente de ácido gálico.

Para avaliação da atividade antioxidante in vitro do extrato aquoso foram utilizados três métodos diferentes: sistema $\beta$-caroteno/ácido linoleico ${ }^{21}$, varredura do radical 2,2 Difenil-1-PicrilHidrazil $\left(\mathrm{DPPH}^{\circ}\right)^{22}$ e o método Oxigen Radical Absorbance Capacity (ORAC) ${ }^{23}$.

A avaliação da atividade antioxidante in vivo foi previamente aprovada pela Comissão de 
Ética em Experimentação Animal (Protocolo CEEA $n^{\circ}$ 96) da Faculdade de Ciências Farmacêuticas da Universidade de São Paulo (USP).

Foram utilizados ratos (Rattus novergicus, var. albinus) machos da linhagem Wistar, com um mês e 15 dias de vida, pesando entre 220 e 240g, provenientes do Biotério de Produção e Experimentação da Faculdade de Ciências Farmacêuticas e do Instituto de Química da USP. Para a indução do diabetes, os animais foram submetidos ao jejum por $16 \mathrm{~h}$, recebendo apenas água ad libitum. O diabetes foi induzido pela injeção de estreptozotocina (40mg/kg de peso, e.v.), dissolvida em tampão citrato $0,01 \mathrm{M}, \mathrm{pH} 4,5$. Após $72 \mathrm{~h}$ da indução do diabetes, foram considerados diabéticos os animais que apresentaram glicemia de jejum igual ou superior a $250 \mathrm{mg} / \mathrm{dL}$.

Em seguida os animais foram distribuídos em 5 grupos $(n=8)$, descritos abaixo, recebendo água ou extrato aquoso de alecrim no volume de $0,5 \mathrm{~mL} / 100 \mathrm{~g}$ de peso corpóreo por via oral (gavagem), durante 30 dias. Dividiram-se 5 grupos:

Controle: animais saudáveis que receberam água filtrada;

D- $\mathrm{H}_{2} \mathrm{O}$ : animais diabéticos que receberam água filtrada como veículo;

D-25: animais diabéticos que receberam extrato aquoso de alecrim na dose de $25 \mathrm{mg} / \mathrm{kg}$;

D-50: animais diabéticos que receberam extrato aquoso de alecrim na dose de $50 \mathrm{mg} / \mathrm{kg}$;

D-100: animais diabéticos que receberam extrato aquoso de alecrim na dose de $100 \mathrm{mg} / \mathrm{kg}$.

Durante todo o tratamento, os animais-controle e os diabéticos foram mantidos em gaiolas individuais, à temperatura de $22 \pm 2^{\circ} \mathrm{C}$, em ciclo claro/escuro de $12 \mathrm{~h}$, tendo acesso livre à água e à ração comercial peletizada Nuvilab CR-1 irradiada.

No final do experimento, após jejum de 8h, os animais foram anestesiados com injeção intraperitonial de uma mistura de cetamina $(90 \mathrm{mg} / \mathrm{kg})$ e xilazina $(10 \mathrm{mg} / \mathrm{kg})$, sendo coletadas amostras de sangue da aorta abdominal, para determinação da hemoglobina glicada. Em seguida, o cérebro e fígado foram perfundidos com solução $\mathrm{NaCl}$ 0,9\%, removidos e congelados a $-80^{\circ} \mathrm{C}$.

Os tecidos foram homogeneizados para determinação da atividade enzimática expressa em $\mathrm{U} / \mathrm{mg}$ de proteína das enzimas antioxidantes $\mathrm{SOD}^{24}$, CAT ${ }^{25}$, GPx e Glutationa Redutase (GR) ${ }^{26}$.

A determinação do conteúdo de proteínas presente nos tecidos foi realizada segundo o método de Bradford ${ }^{27}$.

Para o tratamento estatístico dos dados, foi utilizada a análise de variância (ANOVA), seguida do teste Tukey, usando-se o software Prism 4.0 (GraphPad). Os dados foram expressos como média e desvio-padrão, adotando um nível de significância de $p<0,05$.

\section{RESULTA D OS}

O extrato aquoso de alecrim apresentou uma quantidade expressiva de compostos fenólicos (Média - $M=30,70$, Desvio-Padrão - $\mathrm{DP}=0,02$ ). Em relação à atividade antioxidante in vitro pelos métodos avaliados ( $\beta$-caroteno/ácido linoleico, varredura do radical DPPH e ORAC), o desempenho foi o mesmo para ambos os testes in vitro (Tabela 1).

No estudo de atividade antioxidante in vivo, a destruição das células beta do pâncreas mimetizou o estado diabético, caracterizado por quadro hiperglicêmico, ganho de peso reduzido, polidpsia e polifagia, quando comparados aos animais-controle, embora não tenha sido observada diferença estatística nesses parâmetros, com o tratamento nas concentrações estudadas (Tabela 2).

Os valores de glicemia e o percentual de hemoglobina glicada estão apresentados na Tabela 3. Foi observada redução da hemoglobina glicada apenas nos animais diabéticos tratados com o extrato aquoso na dose de $50 \mathrm{mg} / \mathrm{kg}$. Não foi verificado efeito hipoglicemiante entre os grupos que receberam o extrato, em relação ao grupo 
diabético que recebeu água como veículo ( $p>0,05)$. No entanto, após 30 dias de tratamento, houve um incremento significativo ( $t$ Student $p<0,01)$ no valor glicêmico do grupo tratado com $100 \mathrm{mg} / \mathrm{kg}$, passando de $\mathrm{M}=353,5, \mathrm{DP}=8,96$ para $\mathrm{M}=403, \mathrm{DP}=31,11 \mathrm{mg} / \mathrm{dL}$.

Na Tabela 4 encontra-se a avaliação da atividade das enzimas SOD, CAT, GPx e GR no tecido hepático. Houve redução da atividade enzimática para as enzimas SOD $(p<0,001)$, CAT $(p<0,01)$ e GPx $(p<0,01)$ quando comparados o grupo diabético que recebeu água como veículo e o grupo-controle. No entanto, o grupo diabético que recebeu o extrato aquoso de alecrim na dose de $50 \mathrm{mg} / \mathrm{kg}$, teve as atividades da CAT e GPx mantidas como as do grupo-controle $(p<0,05)$.

O mesmo comportamento foi observado no tecido cerebral, com redução significativa $(p<0,001)$ da atividade das enzimas SOD e GPx do grupo diabético, quando comparado ao controle. E, ao contrário dos resultados no homogenato de fígado, a dose de $50 \mathrm{mg} / \mathrm{kg}$ elevou significativamente a atividade da SOD $(p<0,01)$ (Tabela 5).

Tabela 1. Quantidade de fenólicos totais e atividade antioxidante in vitro do extrato aquoso de alecrim. São Paulo (SP), 2007.

\begin{tabular}{lcc}
\hline Fenólicos totais & $\mathrm{mg} / \mathrm{g}$ de amostra \\
Extrato aquoso & $\mathrm{M}=30,70$ & $\mathrm{DP}=0,02$ \\
\hline$\beta$-caroteno/ácido linoleico & $500 \mu \mathrm{g}$ & $1.000 \mu \mathrm{g}$ \\
Extrato aquoso & $\mathrm{M}=69,94, \mathrm{DP}=0,80$ & $\mathrm{M}=80,93, \mathrm{DP}=0,60$ \\
\hline DPPH & $\mathrm{IC}_{50}(\mu \mathrm{g})$ & 17,47 \\
Extrato aquoso & $\mu \mathrm{mol}$ eq de Trolox $/ \mathrm{g}$ de peso seco \\
\hline ORAC & $\mathrm{M}=2,563, \quad \mathrm{DP}=211,6$ \\
\hline
\end{tabular}

M: média; DP: desvio-padrão; DPPH: difenil-1-pricril-hidrazil; ORAC: oxigen radical absorbance capacity.

Tabela 2. Ganho de peso (g), consumo de ração ( $\mathrm{g} / \mathrm{dia}$ ) e ingestão de água ( $\mathrm{mL} / \mathrm{dia}$ ) por ratos-controle, diabéticos tratados com água e extrato aquoso de alecrim, por 30 dias. São Paulo (SP), 2007.

\begin{tabular}{|c|c|c|c|c|c|c|}
\hline \multirow{2}{*}{ Grupos } & \multicolumn{2}{|c|}{ Ganho de peso (g) } & \multicolumn{2}{|c|}{ Consumo de ração (g/dia) } & \multicolumn{2}{|c|}{ Ingestão de água (mL/dia) } \\
\hline & M & DP & M & DP & $M$ & DP \\
\hline Controle & 96,61 & $12,26^{\mathrm{a}}$ & 28,83 & $1,21^{\mathrm{a}}$ & 34,5 & $5,7^{a}$ \\
\hline $\mathrm{D}-\mathrm{H}_{2} \mathrm{O}$ & 31,94 & $14,75^{b}$ & 42,48 & $4,04^{\mathbf{b}}$ & 148,7 & $12,5^{\mathbf{b}}$ \\
\hline$D-25$ & 35,08 & $10,61^{b}$ & 45,38 & $4,6^{b}$ & 150,7 & $21,7^{\mathbf{b}}$ \\
\hline$D-50$ & 34,15 & $15,48^{b}$ & 42,44 & $5,50^{\mathbf{b}}$ & 150,1 & $26,1^{b}$ \\
\hline D-100 & 23,18 & $9,30^{b}$ & 45,17 & $3,83^{\mathbf{b}}$ & 162,9 & $13,1^{\mathbf{b}}$ \\
\hline
\end{tabular}

M: média; DP: desvio-padrão. As letras diferem entre si estatisticamente.

Tabela 3. Glicemia e percentual de hemoglobina glicada de ratos-controle, diabéticos tratados com água e com extrato aquoso de alecrim, por 30 dias. São Paulo (SP), 2007.

\begin{tabular}{|c|c|c|c|c|c|c|}
\hline \multirow{2}{*}{ Grupos } & \multicolumn{2}{|c|}{ Glicemia inicial (mg/dL) } & \multicolumn{2}{|c|}{ Glicemia final (mg/dL) } & \multicolumn{2}{|c|}{$\%$ Hb-glicada } \\
\hline & M & DP & M & DP & M & DP \\
\hline Controle & 108,67 & $10,56^{\mathrm{a}}$ & 109,75 & $12,16^{\mathrm{a}}$ & 3,29 & $0,43^{a}$ \\
\hline $\mathrm{D}-\mathrm{H}_{2} \mathrm{O}$ & 379,00 & $30,32^{\mathbf{b}}$ & 404,80 & $35,18^{b}$ & 5,58 & $0,32^{b}$ \\
\hline$D-25$ & 380,40 & $48,42^{b}$ & 393,25 & $43,31^{b}$ & 5,52 & $0,27^{\mathbf{b}}$ \\
\hline$D-50$ & 374,75 & $28,76^{\mathbf{b}}$ & 416,75 & $49,93^{b}$ & 4,70 & $0,12^{c}$ \\
\hline D-100 & 353,50 & $8,96^{\mathbf{b}}$ & 403,00 & $31,11^{\mathbf{b}}$ & 5,45 & $0,57^{b c}$ \\
\hline
\end{tabular}

M: média; DP: desvio-padrão. As letras diferem entre si estatisticamente. 
Tabela 4. Atividade das enzimas antioxidantes no tecido hepático de ratos-controle, diabéticos tratados com água e com extrato aquoso de alecrim, por 30 dias. São Paulo (SP), 2007.

\begin{tabular}{|c|c|c|c|c|c|c|c|c|}
\hline \multirow{2}{*}{ Grupos } & \multicolumn{2}{|c|}{ SOD } & \multicolumn{2}{|c|}{ CAT } & \multicolumn{2}{|c|}{ GPx } & \multicolumn{2}{|c|}{ GR } \\
\hline & M & DP & M & DP & M & DP & M & DP \\
\hline Controle & 55,81 & $15,38^{a}$ & 195,63 & $41,58^{a}$ & 1,22 & $0,12^{a}$ & 0,096 & $0,014^{a}$ \\
\hline $\mathrm{D}-\mathrm{H}_{2} \mathrm{O}$ & 27,63 & $7,68^{\mathbf{b}}$ & 111,77 & $21,08^{\mathbf{b}}$ & 0,87 & $0,07^{\mathbf{b}}$ & 0,078 & $0,010^{\mathrm{ab}}$ \\
\hline$D-25$ & 29,98 & $7,48^{\mathbf{b}}$ & 144,05 & $21,63^{\mathrm{ab}}$ & 0,92 & $0,15^{\mathbf{b}}$ & 0,074 & $0,012^{b}$ \\
\hline$D-50$ & 34,48 & $1,28^{\mathbf{b}}$ & 168,90 & $19,47^{a}$ & 1,19 & $0,10^{\mathrm{a}}$ & 0,077 & $0,009^{a b}$ \\
\hline D-100 & 27,05 & $3,61^{b}$ & 91,99 & $34,88^{b}$ & 1,04 & $0,10^{\mathrm{ab}}$ & 0,069 & $0,008^{b}$ \\
\hline
\end{tabular}

As letras diferem entre si estatisticamente. M: média; DP: desvio-padrão; SOD: superóxido dismutase; CAT: catalase; GPx: glutationa peroxidase; GR: glutationa redutase.

Tabela 5. Atividade das enzimas antioxidantes no tecido cerebral de ratos-controle, diabéticos tratados com água e com extrato aquoso de alecrim, por 30 dias. São Paulo (SP), 2007

\begin{tabular}{|c|c|c|c|c|c|c|}
\hline \multirow{2}{*}{ Grupos } & \multicolumn{2}{|c|}{ SOD } & \multicolumn{2}{|c|}{ GPX } & \multicolumn{2}{|c|}{$G R$} \\
\hline & $\mathrm{M}$ & DP & M & DP & M & DP \\
\hline Controle & 22,04 & $2,00^{a}$ & 0,097 & $0,014^{a}$ & 0,029 & $0,003^{a}$ \\
\hline $\mathrm{D}-\mathrm{H}_{2} \mathrm{O}$ & 16,04 & $1,90^{\mathbf{b}}$ & 0,069 & $0,007^{\mathbf{b}}$ & 0,031 & $0,001^{\mathrm{a}}$ \\
\hline D-25 & 17,29 & $1,13^{b c}$ & 0,073 & $0,004^{b}$ & 0,030 & $0,001^{\mathrm{a}}$ \\
\hline D-50 & 19,99 & $1,79^{a c}$ & 0,075 & $0,012^{b}$ & 0,030 & $0,002^{a}$ \\
\hline D-100 & 15,79 & $1,87^{\mathbf{b}}$ & 0,062 & $0,004^{b}$ & 0,031 & $0,002^{a}$ \\
\hline
\end{tabular}

As letras diferem entre si estatisticamente. M: média; DP: desvio-padrão; SOD: superóxido dismutase; GPx: glutationa peroxidase; GR: glutationa redutase.

\section{I S C U S S Ã O}

As especiarias são reconhecidas como fontes potenciais de compostos fenólicos, sendo que o alecrim contém uma quantidade expressiva desses constituintes, dado já bem estabelecido para algumas especiarias e essencial na avaliação do potencial antioxidante.

Dados aproximados aos obtidos neste estudo foram encontrados em trabalhos que avaliaram a quantidade de fenólicos totais e a capacidade antioxidante de vegetais e especiarias $^{28}$.

A atividade antioxidante dos extratos de alecrim depende da sua composição de fenólicos, e tem sido determinada por vários métodos em diferentes sistemas. O sistema lipídico e aquoso prestou-se a avaliar os diversos mecanismos de ação do extrato de alecrim, desde seu potencial antirradical como quelante de metais até sua ação no rompimento de cadeia ${ }^{29}$. No sistema $\beta$-caroteno/ácido linoleico, o extrato aquoso agiu como antioxidante, inibindo a oxidação. Resul- tados semelhantes foram obtidos por Cintra ${ }^{30}$ quando investigou o efeito antioxidante das especiarias salsa, cebolinha verde, orégano e alecrim, por esse sistema (Tabela 1).

A maioria dos métodos para avaliação da atividade antioxidante in vitro de compostos fenólicos é baseada na capacidade destes em varrer radicais livres pela rápida doação de um átomo de hidrogênio para esses radicais ${ }^{31}$, mecanismo também observado com os extratos aquoso e alcoólico de alecrim.

Almela et al. ${ }^{16}$, analisando amostras de alecrim com diferentes formas de tratamento por HPLC e pelo método do DPPH, observaram que a amostra fresca apresentou atividade antioxidante idêntica ao $\alpha$-tocoferol e mais elevada do que o BHT, com resultados, obtidos a partir do cálculo de $\mathrm{IC}_{50}$, similares aos encontrados no presente estudo (Tabela 1).

No ensaio de Capacidade de Absorbância do Radical Oxigênio (ORAC), foi observado que essa especiaria apresenta altos valores de ORAC (Tabela 1). No estudo de Ninfali et al. ${ }^{29}$, foi inves- 
tigada a capacidade antioxidante pelo método ORAC de vegetais, ervas, especiarias e bebidas. Dentre as especiarias avaliadas, a sálvia e o alecrim estavam entre aquelas que apresentaram os maiores valores de ORAC. Tal capacidade foi correta acionada com o alto teor de compostos fenólicos presentes nessas ervas aromáticas, como também com o fato de serem fontes de ácido rosmarínico, um potente antioxidante natural. $\mathrm{O}$ mesmo potencial de atividade antioxidante foi observado em outro estudo que analisou o extrato aquoso de alecrim e de outras espécies da família Lamiaceae, nos modelos de varredura do radical DPPH, relatando capacidade de redução de ferro, ABTS, atividade de varredura do radical hidroxila e inibição da oxidação da $\operatorname{LDL}^{32}$.

\section{Atividade antioxidante in vivo}

Os ratos diabéticos induzidos com Estreptozotocina (STZ) e expostos à doença por 30 dias apresentaram quadro típico de diabetes Mellitus tipo I. A dose de STZ empregada foi suficiente para induzir o modelo de diabetes moderado, apresentando o quadro hiperglicêmico desejável para o estudo (Tabelas 2 e 3). Neste estudo, os animais diabéticos apresentaram aumento significativo da glicose circulante e redução significativa de ganho de peso. A elevação da glicose está relacionada ao estresse oxidativo criado no pâncreas pela STZ11,13.

Os estudos clínicos sobre a avaliação do impacto do controle glicêmico nas complicações crônicas do diabetes, como o United Kingdom Prospective Diabetes Study (UKPDS) e o Diabetes Control and Complications Trial (DCCT), mostraram correlação entre o controle glicêmico, quantificado por determinações seriadas da hemoglobina glicada, e os riscos de desenvolvimento e progressão das complicações crônicas do diabetes. Daí ser a hemoglobina glicada um parâmetro que deve ser constantemente monitorado em pacientes diabéticos. Foi observado que os animais diabéticos tratados com o extrato aquoso na dose de $50 \mathrm{mg} / \mathrm{kg}$ apresentaram redução da hemo- globina glicada, sem demonstrar efeito hipoglicemiante. Entretanto, nas doses de 25 e $100 \mathrm{mg} / \mathrm{kg}$ não foi observado esse efeito (Tabela 3).

Muitos estudos têm demonstrado a ação dos antioxidantes na glicação proteica. Bae \& Lee $(2004)^{33}$ verificaram efeito protetor de extratos de ginseng na glicação da hemoglobina, fato atribuído à capacidade antioxidante dessa planta. Um estudo mais recente avaliou in vitro o potencial antioxidante de substâncias naturais de plantas, incluindo os compostos fenólicos, usando como modelo a glicoxidação de proteína ${ }^{34}$.

O diabetes resulta em alterações metabólicas graves em muitos tecidos, nos quais o estresse oxidativo exerce papel importante na etiologia e desenvolvimento da doença. Os modelos experimentais de diabetes, inclusive com o emprego de STZ, exibem valores elevados de estresse oxidativo, devido à presença de hiperglicemia crônica e persistente, depreciando a atividade do sistema de defesa antioxidante e, assim, promovendo a geração de radicais livres, como também a citotoxicidade e a disfunção tecidual ${ }^{5,35}$.

Foi observada neste estudo uma depleção na atividade das enzimas SOD, CAT, GPx e GR no tecido hepático dos animais experimentais, resultado semelhante ao encontrado por outros pesquisadores ao estudar o estresse oxidativo em animais diabéticos expostos à doença por um período de 15 a 45 dias ${ }^{11,13}$.

Já nos animais tratados com EA de alecrim na dose de $50 \mathrm{mg} / \mathrm{kg}$, normalizou-se a atividade das enzimas CAT e GPx, sem no entanto ser observado aumento na atividade enzimática da SOD. Os mesmos resultados não foram observados nas outras concentrações estudadas, o que mostra que, em menor quantidade $(25 \mathrm{mg} / \mathrm{kg})$, o EA de alecrim não teve efeito sobre esses marcadores. No que diz respeito à maior dose $(100 \mathrm{mg} / \mathrm{kg})$, os animais diabéticos, mesmo submetidos a concentração mais elevada de compostos antioxidantes, não tiveram aumentada a atividade das enzimas antioxidantes (Tabela 4).

No cérebro, o mecanismo de proteção ao estresse oxidativo pode estar associado à atividade 
enzimática da superóxido dismutase (SOD) na concentração de $50 \mathrm{mg} / \mathrm{kg}$. Essa resposta enzimática é importante, uma vez que o aumento na atividade da SOD pode, de certa forma, proteger as enzimas CAT e GPx dos efeitos deletérios do ânion superóxido (Tabela 5).

Embora seja claro o papel do estresse oxidativo no diabetes, os efeitos dos antioxidantes na expressão proteica e a atividade das enzimas antioxidantes não têm sido claramente estabelecidos, principalmente no que diz respeito a essas enzimas, quando se investigam o tempo de exposição à doença, a dose administrada e o tecido analisado. Outro ponto a ser considerado é a autorregulação da atividade dessas enzimas pelas espécies reativas, como ocorre com a GPx, regulada pelos níveis de peróxido de hidrogênio e outras espécies reativas ${ }^{11}$.

Vários trabalhos na literatura mostram redução na atividade das enzimas antioxidantes, em resposta ao quadro de estresse exacerbado relacionado principalmente à formação elevada do ânion superóxido no diabetes e à glicação dessas enzimas. A SOD humana tem sido reportada como mais suscetível à glicação e, portanto, à redução de atividade, como foi observado neste estudo nos tecidos cerebral e hepático de ratos ${ }^{11}$. A atividade da SOD também é regulada pelas espécies reativas e depende dos níveis de glutationa, geralmente reduzida nos animais diabéticos, em razão da síntese da enzima a partir daquela substância ${ }^{36}$.

Os mesmos pesquisadores investigaram o efeito das vitaminas E e/ou C, associadas à administração de insulina em animais diabéticos tratados por 4 semanas. A terapia antioxidante normalizou a expressão proteica das enzimas SOD e GPx e, quando associada à insulina, tanto a expressão como a atividade dessas enzimas foram aumentadas, concluindo-se que a terapia antioxidante pode contribuir para a redução do estresse oxidativo causado pela hiperglicemia e pelo aumento da atividade do sistema de defesa enzimático.

A mesma proteção foi observada na administração de ácido ferúlico a ratos diabéticos por
45 dias. A suplementação resultou na diminuição dos níveis circulantes de glicose, das substâncias reativas ao ácido tiobarbitúrico e dos hidroperóxidos, e no aumento dos níveis de glutationa reduzida e da atividade da SOD, CAT e GPx. O efeito, sobretudo, foi mais pronunciado com a menor dose de ácido ferúlico $(10 \mathrm{mg} / \mathrm{kg})^{13}$. O resultado obtido pelos autores com o ácido fenólico isolado (ferúlico) corrobora os resultados obtidos neste trabalho, no qual se pode observar o efeito protetor da dose de $50 \mathrm{mg} / \mathrm{kg}$ do EA de alecrim, sem no entanto, ser observada dose-resposta quando administrada maior concentração de compostos fenólicos (100mg/kg).

\section{CONCLUSÃ O}

O extrato aquoso de alecrim apresenta significativa capacidade antioxidante in vitro pelos três métodos estudados, o que foi atribuído à presença de compostos fenólicos em sua composição. Quando administrado na concentração de $50 \mathrm{mg} / \mathrm{kg}$ em ratos, o alecrim promoveu aumento na atividade das enzimas CAT e GPx no fígado e SOD no cérebro, podendo apresentar papel importante sobre o estresse oxidativo nos tecidos de animais diabéticos.

\section{A GRADECIMENTO}

Ao Conselho Nacional de Desenvolvimento Científico e Tecnológico pela bolsa e suporte financeiro.

\section{COLABORADORES}

A.M.O. SILVA foi responsável pela elaboração e execução do projeto, análise, interpretação e discussão dos dados e redação do artigo. E.R.S. ANDRADE-WARTHA participou das análises, padronização das enzimas antioxidantes e discussão dos resultados. E.B.T. CARVALHO participou das análises, discussão dos resultados e elaboração do artigo. A. LIMA participou das análises, padronização do método DPPH e interpretação dos dados. A.V. NOVOA participou da interpretação dos dados, busca bibliográfica e elabo- 
ração do artigo. J. MANCINI-FILHO foi responsável pela coordenação do projeto e orientação, acompanhamento de todas as etapas de execução e montagem do artigo, avaliação crítica e revisão final do manuscrito.

\section{REFERÊ N CIAS}

1. Wild S, Roglic G, Green A, Sicree R, King H. Global prevalence of diabetes: estimates for the year 2000 and projections for 2030. Diabetes Care. 2004; 27(5):1047-53.

2. Rocha FD, Teixeira VL, Pereira RC, Kaplan MAC. Diabetes mellitus e estresse oxidativo: produtos naturais como alvo de novos modelos terapêuticos. Rev Bras Farm. 2006; 87(2):49-54.

3. Sociedade Brasileira de Diabetes. Consenso Brasileiro sobre Diabetes 2002: diagnóstico e classificação do diabetes melito e tratamento do diabetes melito do tipo 2. Rio de Janeiro; 2003 [acesso 2008 maio]. Disponível em: <http://neu. saude.sc.gov.br/arquivos/consenso_diabetes_sbd_ 2002.pdf>.

4. Packer L, Kraemer K, Rimbach G. Molecular aspects of lipoic acid in the prevention of diabetes complications. Nutrition. 2001; 17(10):888-95.

5. Brownlee M. The pathobiology of diabetic complications: a unifying mechanism. Diabetes. 2005; 54(6):1615-25.

6. Lapolla A, Fedele D, Traldi P. Glyco-oxidation in diabetes and related diseases. Clin Chim Acta. 2005; 357(2):236-50.

7. Rolo AP, Palmeira CM. Diabetes and mitochondrial function: role of hyperglycemia and oxidative stress. Toxicol Appl Pharmacol. 2006; 212(2):167-78.

8. Sengupta B, Swenson J. Properties of normal and glycated human hemoglobin in presence and absence of antioxidant. Biochem Biophys Res Commun. 2005; 334(3):954-9

9. Shimada S, Tanaka Y, Ohmura C, Tamura Y, Shimizu $\mathrm{T}$, Uchino $\mathrm{H}$, et al. $\mathrm{N}$-(carboxymethyl)valine residues in hemoglobin (CMV-Hb) reflect accumulation of oxidative stress in diabetic patients. Diabetes Res Clin Pract. 2005; 69(3):272-8.

10. Bousová I, Martin J, Jahodár L, Dusek J, Palicka V, Drsata J. Evaluation of in vitro effects of natural substances of plant origin using a model of protein glycoxidation. J Pharm Biomed Anal. 2005; 37(5):957-62.

11. Sindhu RK, Koo J, Roberts CK, Vaziri ND. Dysregulation of hepatic superoxide dismutase, catalase and glutathione peroxidase in diabetes: response to insulin and antioxidant therapy. Clin Exp Hypertens. 2004; 26(1):43-53.

12. Aksoy N, Vural H, Sabuncu T, Arslan O, Aksoy S. Beneficial effects of vitamins $C$ and $E$ against oxidative stress in diabetic rats. Nutr Res. 2005; 25(6):625-30.

13. Balasubashini MS, Rukkumani R, Viswanathan $P$, Menon VP. Ferulic acid alleviates lipid peroxidation in diabetic rats. Phytother Res. 2004; 18(4):310-14.

14. Coskun O, Kanter M, Korkmaz A, Oter S. Quercetin, a flavonoid antioxidant, prevents and protects streptozotocin-induced oxidative stress and $\beta$-cell damage in rat pancreas. Pharmacol Res. 2005; 51(2):117-23

15. Yeh C, Yen G. Induction of hepatic antioxidant enzymes by phenolic acids in rats is accompanied by increased levels of multidrug resistanceassociated protein 3 mRNA expression. J Nutr. 2006; 136(1):11-15.

16. Almela L, Sánchez-Munoz B, Fernández-López JA, Roca MJ, Rabe V. Liquid chromatographic-mass spectrometric analysis of phenolics and free radical scavenging activity of rosemary extract from different raw material. J Chromatogr A. 2006; 1120(1):221-9.

17. Sotelo-Félix JI, Martinez-Fong D, Muriel P, Santillán RL, Castillo D, Yahuaca P. Evaluation of the effectiveness of Rosmarinus officinalis (Lamiaceae) in the alleviation of carbon tetrachloride-induced acute hepatotoxicity in the rat. J Ethnopharmacol. 2002; 81(2):145-54.

18. Amin A, Hamza AA. Hepatoprotective effects of Hibiscus, Rosmarinus and Salvia onazathioprineinduced toxicity in rats. Life Sci. 2005; 77(3):266-78.

19. Moreira AVB, Mancini-Filho J. Atividade antioxidante das especiarias mostarda, canela e erva-doce, em sistemas aquoso e lipídico. Nutrire. 2003; 25(3): 45-60.

20. Swain T, Hills WE. The phenolic constituents of Punnus domestica. I-quantitative analysis of phenolic constituents. J Sci Food Agric. 1959; 10(1): 63-8.

21. Miller HE. Simplified method for evaluation of antioxidants. J Am Oil Chem Soc. 1971; 48(2):91.

22. Brand-Willians W, Cuvelier ME, Brest C. Use of free radical method evaluate antioxidant activity. Lebenson Wiss Technol. 1995; 28(1):25-30.

23. Ou B, Hampsch-Woodill M, Prior RL. Development and validation of am improved oxygem radical absorbance capacity assay using fluoescein as the fluorescent probe. J Agric Food Chem. 2001; 49(10):4619-26.

24. McCord JM, Fridovich I. Superoxide dismutase, an enzyme function for erythrhrocuprein 
(hemocuprein). J Biol Chem. 1969; 244(22): 6049-55.

25. Beutler E. Red cell metabolism: a manual of biochemical methods. $2^{\text {nd }}$ ed. New York: Grune \& Stratton; 1975.

26. Sies H, Koch OR, Martino E, Boveris A. Increased biliary glutathione disulfide release in chronically ethanol treated rats. FEBS Lett. 1979; 103(2):287-90.

27. Bradford MM. A rapid and sensitive method for the quantitation of microgram quantities of protein utilizing the principle of protein-dye binding. Anal Biochem. 1976; 72:248-54.

28. Ninfali P, Mea G, Giorgini S, Rocchi M, Bacchioccal M. Antioxidant capacity of vegetables, spices and dressings relevant to nutrition. Br J Nutr. 2005; 93(2):257-66.

29. Del Bano MJ, Castillo J, Benavente-Garcia O, Lorente J, Martían-Gil R, Acevedo C, et al. Radioprotective-antimutagenic effects of rosemary phenolics against chromosomal damage induced in human lymphocytes by $\gamma$-rays. J Agric Food Chem. 2006; 54(6):2064-8.

30. Cintra RMGC. Efeito antioxidante de especiarias: avaliação da salsa (Petroselium sativum Hoffm), cebolinha verde (Allium shoenoprasum L.), orégano (Origanum vulgare L.) e alecrim (Rosmarinus officinalis L.) [mestrado]. São Paulo: Universidade de São Paulo; 1998.
31. Giada MLR, Mancini-Filho J. Avaliação da atividade antioxidante in vitro de compostos fenólicos de alimentos. Nutrire. 2004; 28(8):91-107.

32. Dorman HJD, Peltoketo A, Hiltunen R, Tikkanen MJ. Characterisation of the antioxidant properties of de-odourised aqueous extracts from selected Lamiaceae herbs. Food Chem. 2003; 83(2):255-62.

33. Bae JW, Lee MH. Effect and putative mechanism of action of ginseng on the formation of glycated hemoglobin in vitro. J Ethnopharmacol. 2004; 91(1):137-40.

34. Bousová I, Martin J, Jahodár L, Dusek J, Palicka V, Drsata J. Evaluation of in vitro effects of natural substances of plant origin using a model of protein glycoxidation. J Pharm Biomed Anal. 2005; 37(5): 957-62.

35. Brownlee M. Biochemistry and molecular cell biology of diabetic complications. Nature. 2001; 414(6865):813-20.

36. Bravenboer B, Kappelle AC, Hamers FPT, Van Buren T, Erkelens DW, Gispen WH. Potential use of glutathione for the prevention and treatment of diabetic neuropathy in the streptozotocin-induced diabetic rat. Diabetologia. 1992; 35(9):813-7.

Recebido em: 2/2/2009

Versão final reapresentada em: 26/5/2010 Aprovado em: 5/7/2010 